\title{
Study on strength of filter system of modular mechanical water treatment plant
}

\author{
Dezhen Feng ${ }^{1,}$, Jianhua Sun ${ }^{1}$ and Fang Zhou ${ }^{2}$ \\ ${ }^{1}$ School of Mechanical Engineering, University of Jinan, Jinan 250022, China \\ ${ }^{2}$ Department of Information Engineering, Shandong Water Vocational College, Rizhao 276800, China
}

\begin{abstract}
Now the modular m echanical w ater $t$ reatment technology i s a new kind of technology in water treatment. The new technology has changed the work way of conventional water plants and got very wide use in practice. In th is paper, the strength and deformation of filter s ystems which includes filter frames and filter plates are ana lyzed with ANSYS. The stresses and def ormations of u pper filter s ystem a nd l ower filter s ystem ar e compared and discussed. The upper and lower filter plates have enough $\mathrm{s}$ afe margins which can prevent the permanent deformation of the filter plates. The lower filter frame can make the best of the property of steel tubes and saved the materials under safety condition. Finally, according to the analysis results, the paper combined analytical results with practice and optimized the design plan of filter systems.
\end{abstract}

Keywords: FEM; water treatment; filter; strength.

\section{Introduction}

China has a vast territory, a large population and rich water resources. But the average water resource of e very person is very low. Further more, the most water of o ur c ountry is s urface water and the components of the w ater ar e v ery co mplicated. This will threaten the $\mathrm{s}$ afety of the water for 1 ife especially for rural water for life. So it is a very i mportant to protect and a pply the surface water scientifically. On the other hand, most parts of our c ountry are mountains and desert. The available land resource is not abundant. With the increase of the population, the development of the economy and the quickening of urbanization process, the land resources will get more and more precious. So how to save in water treatment project has become an important subject.

Now the c onventional water $\mathrm{pl}$ ants of o ur country use steel co ncrete s tructures as the $\mathrm{m}$ ain constructions which need large land and large building project which will cost long time and much money. On the other hand, the conventional wa ter plants a re not flexible in w ork. So the modular mechanical water treatment plants are getting wider and wider use because they need low invest, short time limit, small land and have the advantages of flexibility, high automation and easy operation.

According to the characteristics of modular mechanical water treatment equipment, this paper has analyzed the strength and stiffness of the filter system, discussed the stress and the deformation of the filter $\mathrm{f}$ rame a nd plate, $\mathrm{p}$ resented the $\mathrm{c}$ loud pi ctures of $\mathrm{s}$ tress a nd de formation. At $\mathrm{l}$ ast, $\mathrm{c}$ ombining theory with practice, the paper has improved and optimized the design of filter system.

a Corresponding author : fengdzh@163.com 


\section{Filter system structure}

In this paper, the $w$ ater treatment $\mathrm{p}$ lant $\mathrm{u}$ ses $\mathrm{t}$ wo-layer homogeneous filter $\mathrm{m}$ aterial filter ch amber which includes frames, filter plates, filter material etc. Filter frames and filter plates bear the gravity of filter materials mainly. The filter material is quartz $\mathrm{s}$ and whose density is a bout $2.6 \mathrm{~g} / \mathrm{c} \mathrm{m} 3$ and stacking density is $1.6 \mathrm{~g} / \mathrm{cm} 3$. The filter plates are rigid plastic PVC plates whose thickness is $20 \mathrm{~mm}$. The filter frames are composed of Q 235B steel tubes whose sizes are $160 * 80 * 5 \mathrm{~mm}, 120 * 80 * 5 \mathrm{~mm}$, $80 * 80 * 5 \mathrm{~mm}$.

The upper filter frame uses $1 * 9$ la yout plan, i.e. one $160 * 80 * 5 \mathrm{~mm}$ longitudinal beam and nine $120 * 80 * 5 \mathrm{~mm}$ transverse beams. Under the longitudinal be am, there a re four uniformly $\mathrm{d}$ istributed $80 * 80 * 5 \mathrm{~mm}$ upright columns, as shown in Fig. 1 .

The lower filter frame u ses $3 * 9$ layout plan, i.e. three $80 * 80 * 5 \mathrm{~mm}$ longitudinal beam and nine $80 * 80 * 5 \mathrm{~mm}$ transverse beams. The supports columns a re twelve $(3 * 4)$ uniformly $\mathrm{d}$ istributed $80 * 80 * 5 \mathrm{~mm}$ upright steel tubes, as shown in Fig. 5.

\section{Strength analysis on upper filter system}

For the rectangular sheets with usual constraints, we can use theoretical formulae to compute[1]. But for the complicated combination of be ams and sheets, the theoretical formulae $\mathrm{c}$ an $\mathrm{n}$ ot be used to analyze the strength[2,3]. In this cas e, numerical cal culation must be used. In this pa per, the F EM software ANSYS is used to calculate the stress and deformation of complicated structures.

In the upper filter system, the filter plate uses $20 \mathrm{~mm}$ PVC plate in which a number of filters are mounted. The filter frame u ses $1 * 9$ layout plan, i.e. one $160 * 80 * 5 \mathrm{~mm}$ longitudinal beam and nine $120 * 80 * 5 \mathrm{~mm}$ transverse steel tubes. There are four uniformly distributed $80 * 80 * 5 \mathrm{~mm}$ upright square tubes that support the longitudinal beam, as shown in Fig. 1. In transverse direction, the frame uses nine $120 \times 80 \times 5 \mathrm{~mm}$ rectangular steel tubes which all are welded to the longitudinal beam. The load of quartz sand is about $0.02785 \mathrm{MPa}$. The upper filter plates are fixed on 4 sides. Fig. 2 - Fig. 4 are the analytical results of upper filter system.

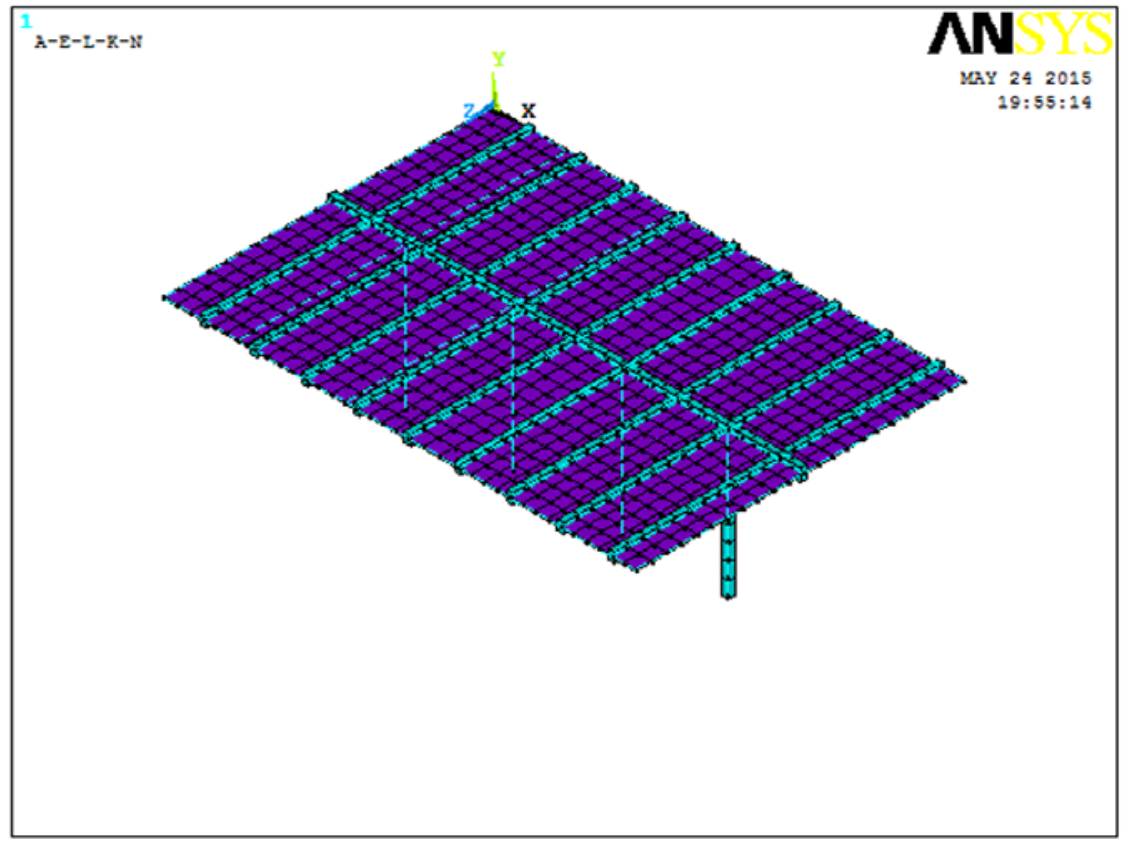

Figure 1. Model of upper filter system 


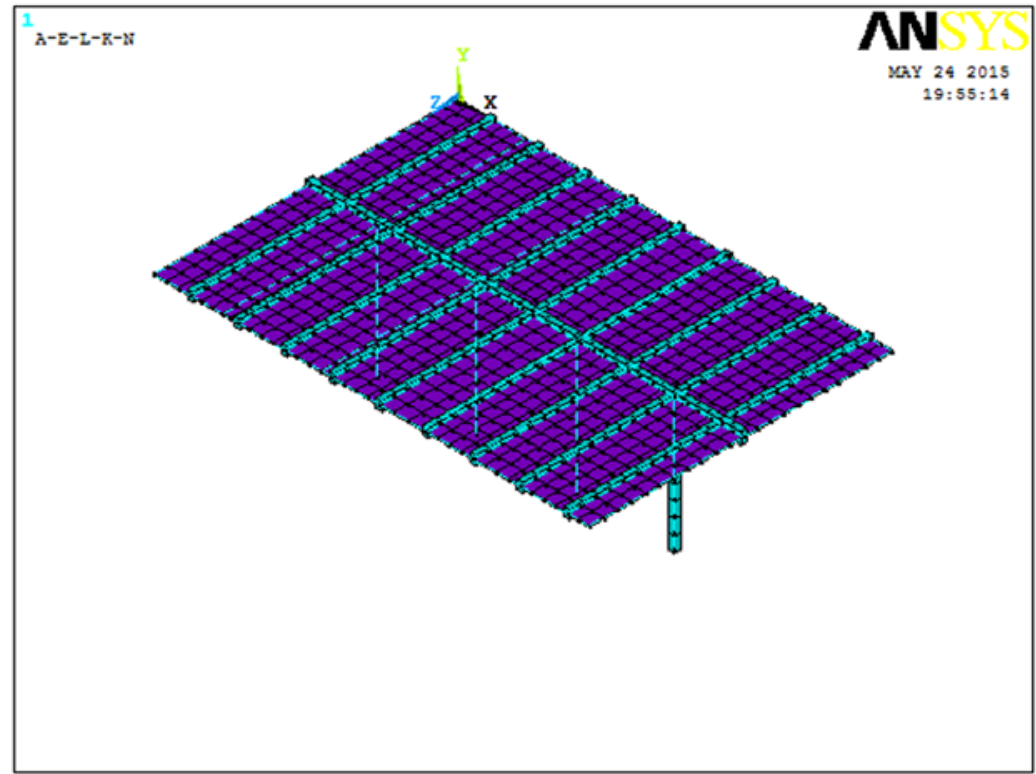

Figure 2. Stress of upper filter system

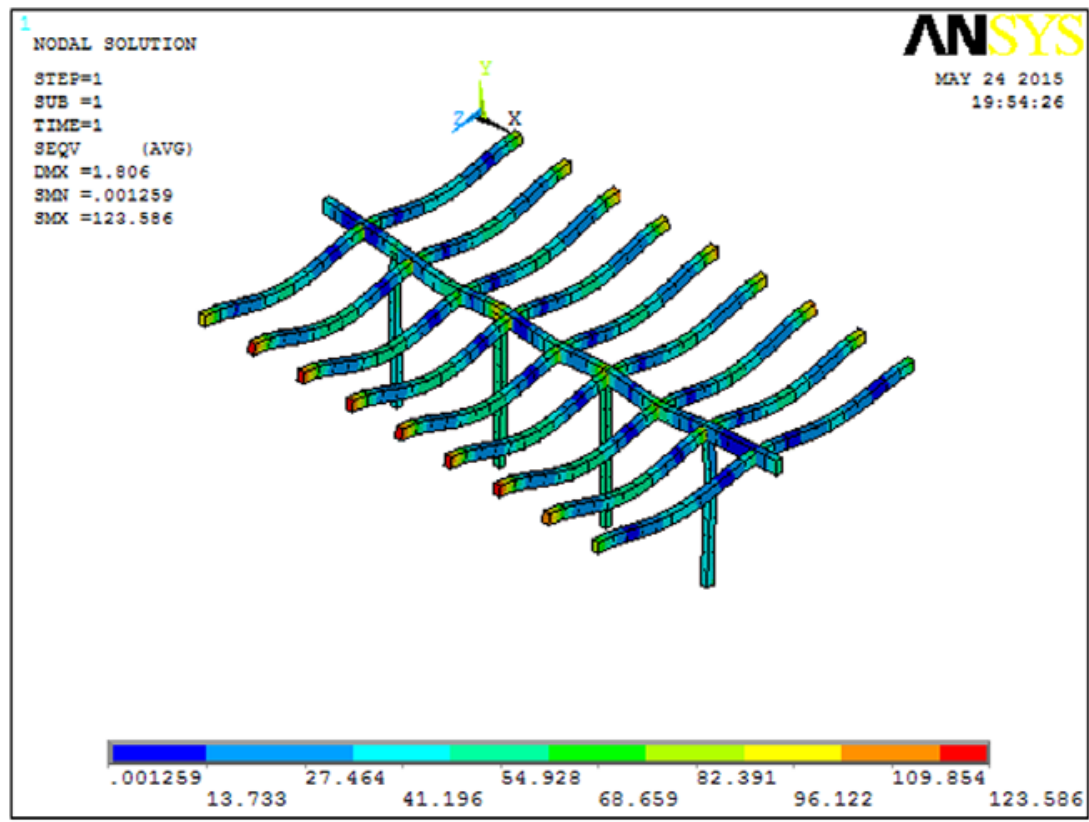

Figure 3. Stress of upper frame 


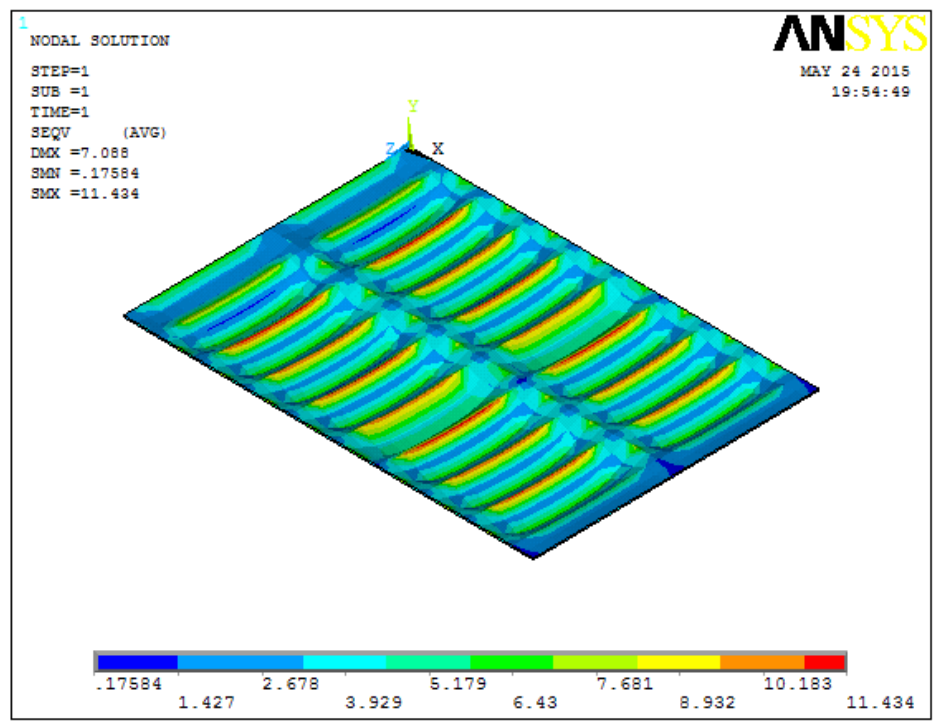

Figure 4. Stress of upper filter plate

From the FEM a nalytical results we find that the largest d eformation of the upper filter plate is about $7.1 \mathrm{~mm}$ and the 1 argest equivalent stress of the filter $\mathrm{p}$ late is a bout $11.4 \mathrm{M} \mathrm{Pa}$. The 1 argest deformation of the upper filter frame is about $1.8 \mathrm{~mm}$, and the largest equivalent stress of the frame is about 123.6 MPa. They all are in safety.

\section{Strength analysis on lower filter system}

In the lower filter s ystem, the filter plate uses $20 \mathrm{~mm} P$ VC p late in which a number of $\mathrm{f}$ ilters a re mounted. The filter frame u ses $3 * 9$ la yout plan, i. e. thr ee $80 * 80 * 5 \mathrm{~mm}$ longitudinal steel tubes and nine $80 * 80 * 5 \mathrm{~mm}$ transverse steel tubes. There are twelve $(3 * 4)$ uniformly distributed $80 * 80 * 5 \mathrm{~mm}$ upright $\mathrm{s}$ quare tub es that $\mathrm{s}$ upport the three longitudinal tubes, a s s hown in $\mathrm{f}$ igure 5 . In transverse direction, the frame uses nine $80 \times 80 \times 5 \mathrm{~mm}$ square steel tubes which all are welded to the longitudinal tubes. The load of active carbon is a bout $0.02785 \mathrm{MPa}$. Fig. 6 - Fig. 8 are the an alytical results of lower filter system.

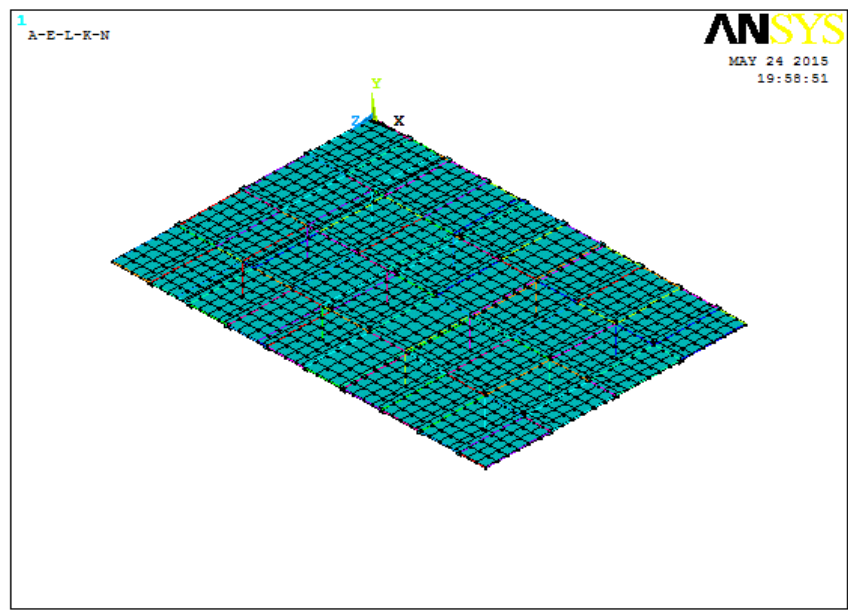

Figure 5. Model of lower filter system 


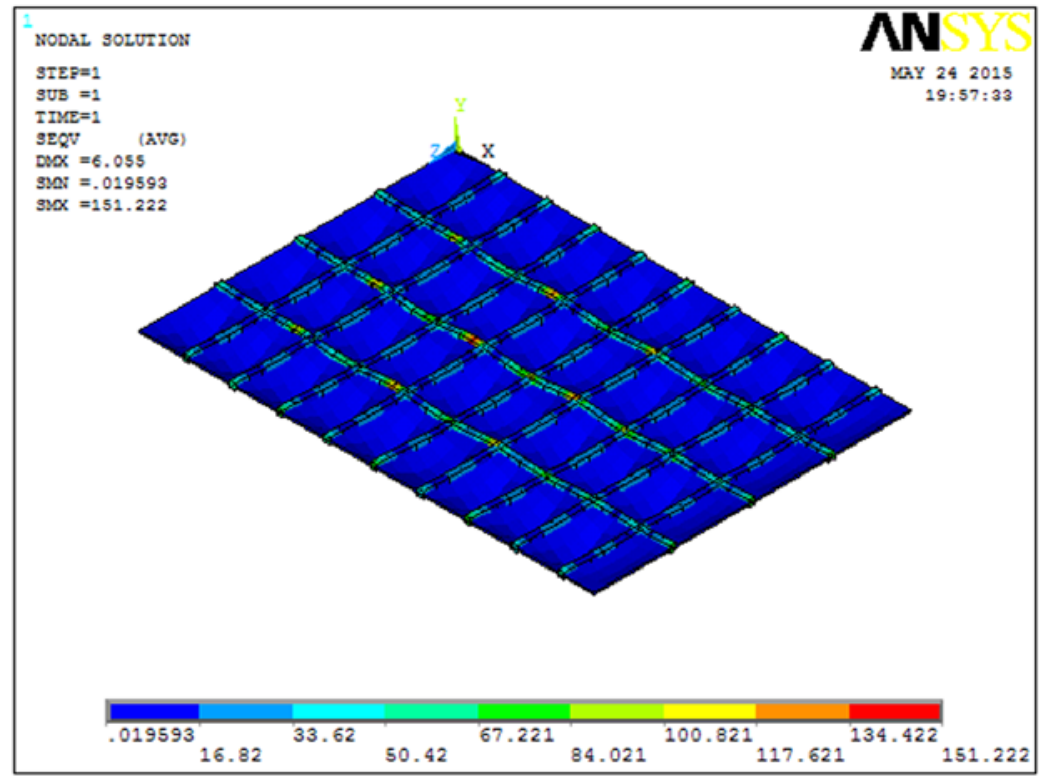

Figure 6. Stress of lower filter system

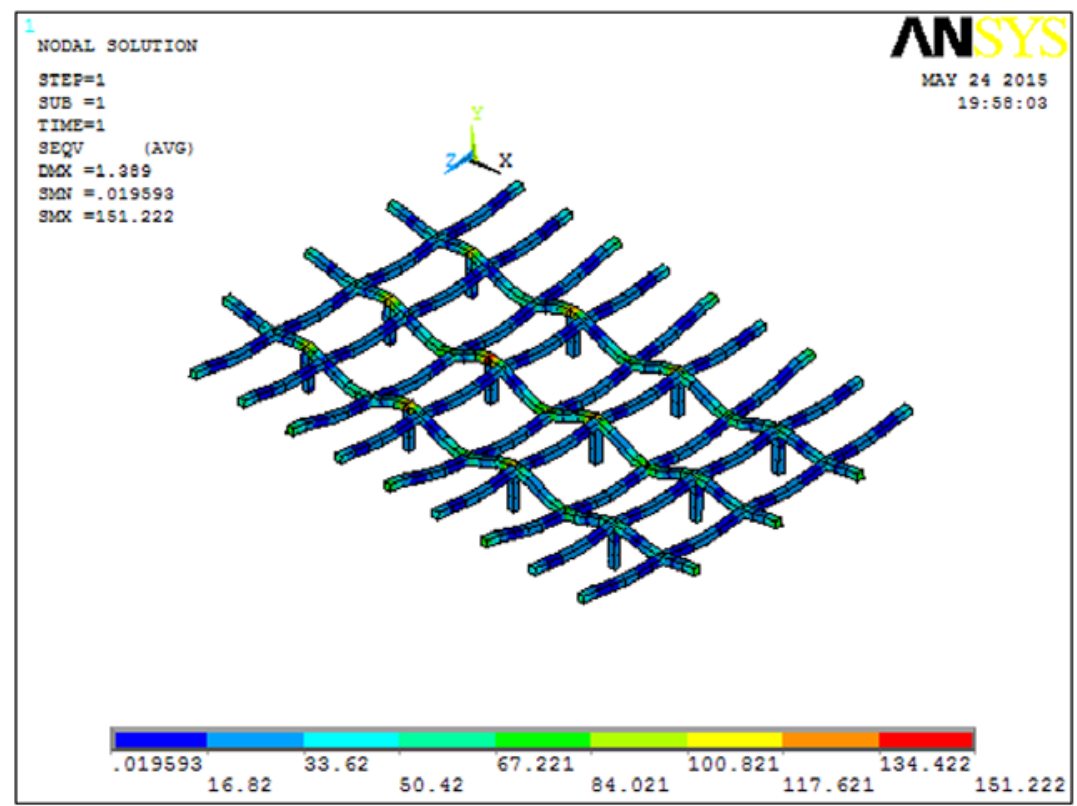

Figure 7. Stress of lower frame 


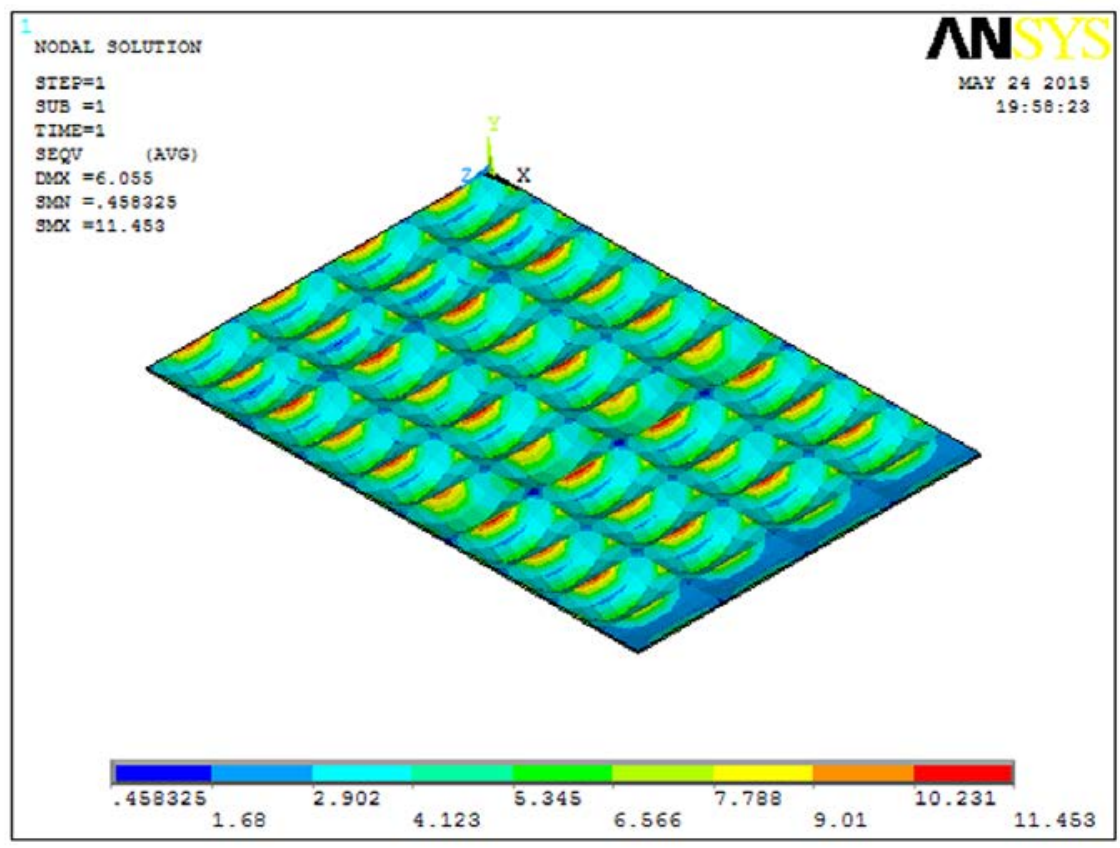

Figure 8. Stress of lower filter plate

From the FEM a nalytical results we find that the largest deformation of the lower filter plate is about $6.1 \mathrm{~mm}$ and the largest equivalent stress of it is about $11.5 \mathrm{MPa}$. The largest deformation of the lower filter frame is about $1.4 \mathrm{~mm}$, and the largest equivalent stress of the filter frame is about 123.6 $\mathrm{MPa}$. They all are in safety too.

\section{Analysis of results}

The deformations and stresses of the upper and lower filter systems under the normal work loads are shown in Table 1.

Table 1. Deformations and stresses of the upper and lower filter systems

\begin{tabular}{lll}
\hline & $\begin{array}{l}\text { Equivalent stress } \\
(\mathrm{MPa})\end{array}$ & $\begin{array}{l}\text { Deformation } \\
(\mathrm{mm})\end{array}$ \\
\hline Upper filter plate & 11.4 & 7.1 \\
Upper filter frame & 123.6 & 1.8 \\
Lower filter plate & 11.5 & 6.1 \\
Lower filter frame & 151.2 & 1.4 \\
\hline
\end{tabular}

From Table 1 we find that under the normal loads the stress of the upper filter plate and the stress of the lower filter plate are close to equal, but the deformation of the upper filter plate is larger than the deformation of the lower filter plate. The reason is that upper filter frame is sparser than lower filter frame. Further more, the upper frame only has 4 supporting tubes. In general, the sparse structure is good for operation. The stress of lower filter frame is larger than the stress of upper frame, but the deformation of lower frame is smaller than the deformation of upper filter frame. The main reason is that $t$ he 1 ower $f$ ilter $f$ rame used the thinner $80 * 80 * 5 \mathrm{~mm}$ t ubes a nd more (12) s upporting t ubes. Because there is no need in process requirements for the operation of lower frame, so it can have more supporting tubes. 


\section{Summary}

The paper a nalyzed the s trength a nd stiffness of the filter s ystems of modular $m$ echanical water treatment equipment by use of FEM. The analysis results show that the designs of filter systems are reasonable which can satisfy the requirements of strength and stiffness. The upp er and low er filter plates have enough safe margins which can prevent the permanent deformation of the filter plates. The lower filter frame can make the best of the property of steel tubes and saved the materials under safety condition. The u pper filter frame u sed sparser structure which is convenient to operation a nd $\mathrm{c}$ an improve processes. At the same time, the upper frame also has some safe margin which can bear the changes of load. So, the analysis is very meaningful to modular mechanical water treatment.

\section{References}

1. Chen Jingyi. Manual of Computer Aided Engineering Analysis of ANSYS. $1^{\text {st }}$ Edition. Beijing: China Railway Press, 2001

2. T. R. Ch andrupatla. Introduction to F inite Elements in Engineering. ${ }^{\text {st }}$ Edition. B eijing: China Machine Press, 2008

3. ANSYS Inc. ANSYS Structural Analysis Guide Release 5.4 Third Edition. SAS, IP Inc., 1997 